\title{
BMJ Open Needs and rights awareness of stroke survivors and caregivers: a cross- sectional, single-centre questionnaire survey
}

Xin Li, ${ }^{1}$ Xiaoshuang Xia, ${ }^{1}$ Peilu Wang, ${ }^{1}$ Shuting $Z$ hang, ${ }^{2}$ Ming Liu, ${ }^{2}$ Lin Wang $^{3}$

To cite: Li X, Xia X, Wang P, et al. Needs and rights awareness of stroke survivors and caregivers: a crosssectional, single-centre questionnaire survey. BMJ Open 2017;7:e013210. doi:10.1136/ bmjopen-2016-013210

- Prepublication history and additional material for this paper are available online. To view please visit the journal (http:// dx.doi.org/10.1136/bmjopen2016-013210).

Received 28 June 2016 Revised 19 February 2017 Accepted 20 February 2017

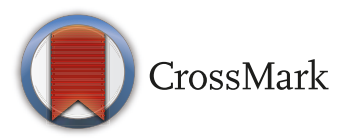

${ }^{1}$ Department of Neurology, The Second Hospital of Tianjin Medical University, Tianjin, China ${ }^{2}$ Stroke Clinical Research Unit, Department of Neurology, West China Hospital, Sichuan University, Chengdu, China ${ }^{3}$ Department of Geratology, The Second Hospital of Tianjin Medical University and Tianjin Geriatric Institute, Tianjin, China

Correspondence to

Professor Xin Li;

lixinsci@126.com and Ming Liu; wyplmh@hotmail.com

\section{ABSTRACT}

Objectives The needs and rights awareness of stroke survivors have not been reported in China. This study investigated the needs and rights awareness of stroke survivors and caregivers in Tianjin, China.

Setting A survey launched by the World Stroke Organization was conducted in Tianjin, China. The questionnaire included demands for psychological support, treatment and care, social support and information. Stroke survivors and their caregivers were interviewed face to face for the questionnaire. Between June 2014 and February 2015, stroke survivors were invited to participate if they were more than 18 years old and had experienced a stroke. Exclusion criteria were patients who had disorders of consciousness, significant cognitive impairment, aphasia, communication difficulties or psychiatric disorders. Only caregivers who were family members of the patients were chosen. Paid caregivers were excluded. Participants Two hundred and forty-eight stroke survivors and 212 caregivers were enrolled.

Primary outcome measures The correlations between levels of needs and potential effect factors were analysed. Levels of different needs were compared by age, gender and time since stroke.

Results Among the cohort, 95.6\% stroke survivors and $92.5 \%$ caregivers agreed to each question in the questionnaire. The participants prioritised the needs for psychological support (99.4\%), treatment and care (98.6\%), social support (98\%) and information (96.2\%). The total score was negatively correlated with age $(r=-0.255, p<0.01)$. Patients below 65 years old had higher scores than those 65 years or older $(p<0.01)$, while male patients had higher scores than female patients $(p<0.01)$.

Conclusions The needs for psychological and emotional support, individual treatment, social support and information about stroke were eagerly reported by most survivors. The Bill of Rights must be recognised by the Chinese society, providing appropriate stroke care to every patient to optimise stroke outcomes.

\section{INTRODUCTION}

Stroke is the major cause of death and disability worldwide. The burden of stroke is particularly serious in Asia, ${ }^{1}$ and its mortality is higher than that in Europe or North

\section{Strengths and limitations of this study}

- Stroke survivors and caregivers did not have their own bill of rights when this study was performed, and their needs and rights awareness have not been reported in China.

- The demands for psychological and emotional support, individual treatment, social support and information were eagerly reported by most stroke survivors.

- The stroke survivors in China had the strongest demand for emotional and psychological support, which should be recognised.

- Limitations include potential bias due to the exclusion of patients with severe language or cognitive impairment. The number of participants was also limited. Further multiple-centre and largesample research studies may be needed.

America. ${ }^{2}$ In China, it is the leading cause of death and disability. ${ }^{3}$ Stroke survivors cope with significant physical, cognitive and emotional deficits, and $25 \% 74 \%$ of these survivors require some assistance or are fully dependent on their caregivers for activities of daily living. ${ }^{4}$ Although much has been done to control the disease, the stroke survivors' needs and rights have not received adequate attention. Bills of patient rights for several diseases have been developed to achieve higher degrees of patient satisfaction, such as for cancer ${ }^{5}$ and chronic obstructive pulmonary disease. ${ }^{6}$ Stroke survivors did not have their own bill of rights until the World Stroke Organization (WSO) realised this urgent need and framed a global bill of rights for patients with stroke. ${ }^{7}$ The WSO has numerous strategies to increase stroke awareness, including influencing policies for stroke prevention and improved health services, providing education, and fostering the development of systems and organisations for the longterm support of stroke survivors and their families. ${ }^{8}$ To determine what stroke survivors 
and caregivers require, the WSO has launched an online survey (https://www.surveymonkey.com/s/WSOStrokeSurvivor-Chinese and https://www.surveymonkey.com/ s/WSOStrokeCarer-Chinese) (see online supplementary file).

This survey was used in this study to investigate the needs and rights awareness in Chinese stroke survivors and caregivers. This study was aimed to provide a reference for the improvement of stroke-related laws and bills, which could provide the stroke survivor with physical, mental and emotional support.

\section{METHODS \\ Study population}

This study was approved by our local Ethics Committee at the Second Hospital of Tianjin Medical University. All patients and their caregivers gave informed consent.

Between June 2014 and February 2015, 248 stroke survivors and 212 caregivers from the Stroke Clinical Registry and Follow-up Database of the Second Hospital of Tianjin Medical University were enrolled. According to the Kendall sample size determination method of the questionnaire, at least 70-140 samples were needed; therefore, we recruited more participants than the sample size determined. Stroke survivors were invited to participate if they were more 18 years old, had experienced stroke and agreed to participate in the study. The exclusion criteria were patients who had disorders of consciousness, significant cognitive impairment, aphasia, communication difficulties or psychiatric disorders.

Caregivers who had been taking care of the patients with stroke who met the above criteria were recruited. Only caregivers who were family members of the patients were chosen. Paid caregivers were excluded.

\section{Development of the survey}

The questionnaire was adapted from that designed by the WSO. Stroke survivors and caregivers were interviewed face to face during the patients' follow-up by well-trained neurologists who were not the patients' treating doctors.

The final questionnaire included 17 questions covering age, gender, level of education, time since the first stroke, and demands for treatment and information about stroke and psychological and social support. Fourteen of the questions had five choices for each question. The five choices were strongly agree, agree, neutral, disagree and strongly disagree. The Likert five-grade score method was used to assign 1-5 points; higher scores indicated a greater degree of demand. The purpose of the survey and the procedure were explained fully to all participants.

The questionnaire translated to Chinese was tested again for the reliability in our population. The scales reliability of the stroke survivors' questionnaire was assessed with a total Cronbach's $\alpha$ of 0.910 , corrected by interitem correlation above 0.70 . The scales reliability of the stroke caregivers' questionnaire was assessed with
Table 1 Characteristics of stroke survivors and caregivers

\begin{tabular}{|c|c|c|}
\hline & $\begin{array}{l}\text { Stroke } \\
\text { survivors } \\
\text { n (\%) }\end{array}$ & $\begin{array}{l}\text { Stroke } \\
\text { caregivers } \\
\text { n (\%) }\end{array}$ \\
\hline Total & 248 & 212 \\
\hline \multicolumn{3}{|l|}{ Age } \\
\hline$<45$ & $3(1.2)$ & $49(23.1)$ \\
\hline $45-54$ & $29(11.7)$ & $69(32.5)$ \\
\hline $55-64$ & $54(21.8)$ & $65(30.7)$ \\
\hline $65-74$ & $63(25.4)$ & $21(9.9)$ \\
\hline $75-84$ & $73(29.4)$ & $5(2.4)$ \\
\hline$\geq 85$ & $26(10.5)$ & $3(1.4)$ \\
\hline \multicolumn{3}{|l|}{ Gender } \\
\hline Male & $125(50.4)$ & $95(44.8)$ \\
\hline Female & 123 (49.6) & 117 (55.2) \\
\hline \multicolumn{3}{|l|}{$\begin{array}{l}\text { Time since } \\
\text { stroke, years }\end{array}$} \\
\hline$<1$ & $170(68.5)$ & $132(62.3)$ \\
\hline $1-3$ & $41(16.5)$ & $37(17.5)$ \\
\hline $4-7$ & $13(5.2)$ & $22(10.4)$ \\
\hline $8-10$ & $6(2.4)$ & $8(3.8)$ \\
\hline$>10$ & $18(7.3)$ & $13(6.1)$ \\
\hline \multicolumn{3}{|l|}{ Education, years } \\
\hline$<3$ & $19(7.7)$ & $2(0.9)$ \\
\hline $3-6$ & $44(17.7)$ & $13(6.1)$ \\
\hline $6-9$ & $70(28.2)$ & $56(26.4)$ \\
\hline $9-12$ & $88(35.5)$ & $93(43.9)$ \\
\hline$>12$ & $27(10.9)$ & $48(22.6)$ \\
\hline \multicolumn{3}{|l|}{ Type of stroke } \\
\hline Ischaemic stroke & $192(77.4)$ & $170(80.2)$ \\
\hline Haemorrhagic stroke & $56(22.6)$ & $42(19.8)$ \\
\hline \multicolumn{3}{|l|}{ NIHSS score } \\
\hline$<4$ & $115(46.4)$ & $90(42.5)$ \\
\hline $4-15$ & 127 (51.2) & $116(54.7)$ \\
\hline$>15$ & $6(2.4)$ & $6(2.8)$ \\
\hline
\end{tabular}

NIHSS, National institutes of Health Stroke Scale.

a total Cronbach's $\alpha$ of 0.817 , corrected by interitem correlation above 0.70 . The Cronbach's $\alpha$ values were good for all scales for the study.

\section{Statistical analysis}

Frequencies and proportions were used to summarise levels of answers. The Spearman rank relational coefficient was used to analyse the correlations between levels of needs and potential effect factors. Levels of different needs were compared by age, gender and time since stroke. Categorical variables are displayed as frequencies and percentages. Categorical variables were analysed using a $\chi^{2}$ test. Comparisons between groups were made 
Table 2 The correlations between levels of needs and potential effect factors

\begin{tabular}{|c|c|c|c|c|c|c|c|c|c|c|}
\hline & \multicolumn{2}{|l|}{ Total } & \multicolumn{4}{|c|}{ Psychological support Information } & \multicolumn{2}{|c|}{ Treatment and care } & \multicolumn{2}{|c|}{ Social support } \\
\hline & Rho & p Value & Rho & p Value & Rho & p Value & rho & p Value & Rho & p Value \\
\hline Age & -0.255 & $<0.001$ & -0.211 & 0.001 & -0.221 & $<0.001$ & -0.197 & 0.002 & -0.245 & $<0.001$ \\
\hline Time since stroke & -0.044 & 0.487 & 0.095 & 0.135 & -0.063 & 0.324 & -0.127 & 0.046 & -0.029 & 0.647 \\
\hline Education & 0.099 & 0.121 & -0.000 & 0.998 & 0.051 & 0.427 & -0.067 & 0.293 & 0.010 & 0.879 \\
\hline NIHSS Score & -0.088 & 0.169 & 0.010 & 0.877 & -0.059 & 0.352 & -0.087 & 0.172 & -0.036 & 0.578 \\
\hline
\end{tabular}

NIHSS, National institutes of Health Stroke Scale.

\begin{tabular}{lccccc}
\hline Table 4 & \multicolumn{2}{l}{ Needs of rural stroke survivors by gender } & & \\
\hline & Total & \multicolumn{1}{l}{ Psychological support } & Information & Treatment and care & Social support \\
\hline Male & $4.3(4.0-5.0)$ & $4.5(4.0-5.0)$ & $4.0(4.0-5.0)$ & $4.4(4.0-5.0)$ & $4.4(4.0-5.0)$ \\
Female & $4.1(4.0-4.9)$ & $4.0(4.0-5.0)$ & $4.0(4.0-5.0)$ & $4.2(4.0-4.8)$ & $4.2(4.0-4.8)$ \\
Z & -2.210 & -2.893 & -0.810 & -2.043 & -2.063 \\
P & 0.027 & 0.004 & 0.418 & 0.041 & 0.039
\end{tabular}

using the Mann-Whitney U test. Statistical tests were performed at the $95 \%$ CI level.

\section{RESULTS}

\section{Study population}

The descriptive characteristics of stroke survivors and caregivers are summarised in table 1 .

The 248 stroke survivors included 123 women and 125 men between the ages of 33 and 92 years, with a mean age of 69.5 years. The 212 caregivers included 117 women and 95 men between the ages of 20 and 88 years, with a mean age of 52.6 years. Stroke survivors they cared for were aged between 45 and 92 years, with a mean age of 72.2 years.

Among the cohort, 95.6\% of the stroke survivors approved of each question in the questionnaire. The results of the survey showed that participants prioritised the need for psychological support $(99.4 \%)$, treatment and care $(98.6 \%)$, social support $(98 \%)$ and information $(96.2 \%)$. The total score and every aspect of need were negatively correlated with age $(p<0.01)$. There were no correlations between needs and type of stroke or National Institutes of Health Stroke Scale score ( $p>0.05)$ (table 2).

The total needs and every aspect of the needs of patients below 65 years old were higher than those of older patients
(65 years or older) $(\mathrm{p}<0.05)$. Moreover, male patients had higher scores for total needs, psychological needs, needs for treatment and care and needs for social support than female patients $(\mathrm{p}<0.05)$ (tables 3 and 4$)$.

\section{Caregivers' opinion}

Among the caregivers, $92.5 \%$ approved of each question in the questionnaire. Timely diagnosis and treatment appeared to be uppermost in caregivers' minds $(99.1 \%)$. They also cared about financial support to aid in the patient's recovery $(98.6 \%)$. The total score of caregivers was negatively correlated with the age of the caregivers $(\mathrm{r}=-0.197, \mathrm{p}=0.004)$, while positively correlated with levels of education $(\mathrm{r}=2.259, \mathrm{p}<0.001)$. No correlation was found between the scores and gender or time that the patients they cared for experienced their first stroke $(\mathrm{p}>0.05)$.

\section{DISCUSSION}

In this study, $95.6 \%$ stroke survivors and $92.5 \%$ of caregivers approved of each question, which showed that most patients were eager for a formal declaration of their rights. The Global Stroke Bill of Rights, developed by the WSO, sets out the right of each stroke survivor to receive

Table 3 Needs of stroke survivors by age

\begin{tabular}{llcccc}
\hline & Total & Psychological support & Information & Treatment and care & Social support \\
\hline$<65$ & $4.7(4.1-5.0)$ & $5.0(4.0-5.0)$ & $4.5(4.0-5.0)$ & $4.6(4.0-5.0)$ & $4.6(4.0-5.0)$ \\
$\geq 65$ & $4.2(4.0-4.7)$ & $4.0(4.0-5.0)$ & $4.0(4.0-4.5)$ & $4.2(4.0-4.8)$ & $4.0(4.0-4.8)$ \\
$Z$ P & -4.179 & -3.314 & -3.477 & -3.090 & -3.855 \\
$P$ & $<0.001$ & 0.001 & 0.001 & 0.002 & $<0.001$ \\
\hline
\end{tabular}


the best stroke care, be informed and prepared, and be supported in their recovery. ${ }^{9}$

\section{Factors that influenced the awareness of needs and rights}

This survey showed that patients below 65 years old had more needs than younger patients. The needs and awareness of rights were negatively correlated with the age of the patients. Because of different social and domestic duties between younger and older patients, younger patients yearned for a higher quality of life after experiencing stroke. They seemed keener to acquire knowledge of stroke and appropriate therapies as well as emotional and social support. This result did not match the findings of a similar survey conducted in the $\mathrm{UK},{ }^{10}$ which reported that there was no relationship between needs and age. Patients more than 65 years of age constituted $47.5 \%$ of the subjects in the British survey, while in this survey, $65.3 \%$ of the patients were above 65 years old. In addition, unlike other surveys, this survey found that male patients had a stronger demand for and were more conscious of their rights. This phenomenon could be due to the traditional thought of 'male superiority to female' in Chinese tradition society. A study in China showed that there was a sex difference in the social participation domain in Chinese patients with stroke, and male patients had higher social desires. ${ }^{11}$

Our study is consistent with the UK study, ${ }^{10}$ where no significant correlation was found between the total scores and levels of education. There was also no correlation between the needs and the time since the first stroke. Similarly, Walsh et $a l^{12}$ found no significant difference in time since stroke between those who reported multiple unmet needs and those who reported one or no unmet needs.

\section{Psychological support}

As shown in our results, the questions related to psychological needs received the highest score and the highest support rate, suggesting that stroke survivors in China had the strongest demand for emotional and psychological support. A sudden attack and poor prognosis had an appreciable effect on the psychology of stroke survivors. Some surveys have demonstrated that emotional problems among stroke survivors would be prejudicial to treatment and rehabilitation after stroke. ${ }^{13-15}$ As physicians, we usually pay more attention to treating the disease, rather than the emotional needs of the patients. A national survey carried out in Ireland showed that $77 \%$ of respondents suffered from emotional problems after stroke, while only $10 \%$ of the respondents had received community psychological service. ${ }^{12}$ Since emotional and psychological needs are liable to be neglected, poststroke depression was a common complication which seriously impairs quality of life. ${ }^{16} 17$ Psychological expertise and formal psychological support were needed by stoke survivors. ${ }^{18}$ The newest version of the Chinese Stroke Guidelines goes further, recommending psychological support.

\section{Needs for treatment and care}

The needs for diagnosis, treatment, care and rehabilitation were second only to the need for psychological support. The strategies should vary depending on the cause, pathophysiological mechanisms, severity and prognosis to reduce the risk of a recurrent event. ${ }^{19}$ Patients should be assessed for individual risks, such as atrial fibrillation, in which case antithrombotic therapy oral anticoagulation may be needed for effective stroke prevention. ${ }^{20}$ Most stroke survivors suffer from different residual deficits; individualised and optimised care is also needed during inpatient and in chronic care and end-oflife settings. ${ }^{4}$ Rehabilitation was usually ignored in busy clinical settings prior to discharge from hospital in China, and there was also a lack of postdischarge rehabilitation services. The patients perceived nurse-led coordination of rehabilitation and ongoing changes of rehabilitation goals in different stages of recovery. ${ }^{21}$ A considerable unmet need for poststroke rehabilitation services was also found in other low-income and middle-income countries, such as India. ${ }^{22}$ As stroke is an emergency and disastrous disease, a timely and appropriate diagnosis and therapy made by specialised neurologists is vital to the survival and recovery of the patients. A well-organised continuing medical education system for community doctors and non-neurologists covering stroke should be established in China, ${ }^{23}$ as well as a stroke services system in accordance with the WSO Global Stroke Services Guidelines and Action Plan, ${ }^{24}$ reminding us that stroke awareness, education, prevention and treatment should always be feasible.

\section{Social support}

In this study, the stroke survivors exhibited a desire to return to their full range of activities and roles they had before their stroke, playing an active role in their own lives and in their community. However, there is often a gap between their aspiration and what they actually experience. A cross-sectional study showed that stroke survivors had more participation restrictions. ${ }^{25}$ Physical/ structural and services/assistance were considered the dominant barriers to and participation in activities of daily life for stroke survivors in China. ${ }^{26}$ This research also found that needs had a negative correlation with age. In Ireland, only $23 \%$ of those below the age of 66 obtained a full-time or part-time job after stroke. ${ }^{11}$ Those under retirement age would face a higher financial burden and social responsibility. The age-specific burden of stroke in low-income and middle-income countries is greater than in high-income countries. ${ }^{27}$ In our survey, $97.6 \%$ of all the stroke survivors expected to receive financial support, much higher than in the Irish survey. ${ }^{11}$ Social support should be provided to stroke survivors, including barrier-free facilities and financial support; furthermore, the social security system for stroke survivors needs to be improved in low-income and middle-income countries such as China. 


\section{Information needs}

In this study, most individuals wanted more information about the signs of stroke, as well as what changes they would face afterwards. With more knowledge of stroke, they could identify the disease immediately, resulting in a decrease in the time from symptom onset to hospital arrival and increase in the number of patients who may receive appropriate interventions. ${ }^{28}$ Knowing the individual's abilities and limitations would help them to prepare adequately for the future. Although stroke is a devastating disease for the individual, family and society, many times their knowledge about stroke goes unheeded. Individuals had an extremely limited knowledge of stroke, which was also reported in other countries. ${ }^{29-32}$ A survey among patients with previous stroke or transient ischaemic attack in China showed that only $3.3 \%$ of patients knew all the stroke warning signs, and only $9.2 \%$ indicated that they would seek emergency service. ${ }^{32}$ In this study, we also found that younger patients had a stronger need to know about the changes they would face after stroke. Stroke survivors had to adapt to changes in their bodies as a result of stroke and adjust their expectations, including roles within the home and community, particularly for those of working age. Another discovery in our research was that as the level of education increased, so did the request for more information on stroke. Well-educated patients had the desire to learn all they could about stroke. Those with the least understanding of stroke were participants in an Irish survey that only had a primary level of education. ${ }^{33}$

Educational strategies to increase stroke knowledge are urgently needed to combat and prevent disease. We have made efforts to educate physicians and patients about stroke to improve the recognition of this condition in China, especially in our hospital. Educational activities have been held every world stroke day over the past few years and once a month this year. Local and regional healthcare workers should put a high premium on health education about stroke to meet the needs of patients and to disseminate the knowledge to the public, policymakers and health professionals. ${ }^{34}$

\section{The stroke caregivers' opinions}

A stroke in the family can cause many shifts, whether it is relationship dynamics, finances, home modifications or role changes. The views of caregivers of stroke survivors would provide a valuable reference about the needs and rights of these patients, as the caregivers provide physical and psychological support in the daily life of stroke survivors. Not consistent with the stroke survivors, the caregivers' ultimate concern was treatment and financial support, which revealed the heavy burden the family suffered due to stroke and need for social support. The scores for these questions were negatively correlated to their age, while positively correlated to their level of education. A longitudinal study of caregivers' perspectives found that family caregivers expected to obtain assistance and care-related information. ${ }^{35}$ Providing caregivers with relevant information and counselling would be beneficial to the recovery and rehabilitation of stroke survivors.

\section{Limitations}

First, patients who were not able to express their views due to severe language or cognitive impairment were excluded from this study. The results could not reflect their needs, which may lead to some bias. Second, nearly $70 \%$ of stroke survivors who participated in this survey experienced their stroke less than 1 year ago; therefore, their long-term needs might not have been met accurately. Finally, the number of participants was limited, and data were only collected from one site, which may limit the generalisability of our results. In addition, we did not use in-depth interviews or focus groups to explore the reasons behind the patients' needs. Further multiple-centre and large-sample research studies may be needed in the future to explore the needs of stroke survivors using these techniques.

\section{CONCLUSION}

The demands of psychological support, treatment and care, social support and information about stroke in China were much more than we expected. Stroke services should consider each individual stroke survivor's needs for psychological and physical care in the whole course of their condition, from the onset of stroke through rehabilitation and reintegration into the community, which requires a more concerted effort across specialists in stroke units, communities and social supports. The Bill of Rights must also be recognised by Chinese society, providing appropriate stroke care to every patient to optimise stroke outcomes.

Acknowledgements The authors would like to acknowledge the World Stroke Organization, which allowed us to adapt the questionnaire about the rights of stroke survivors and caregivers. We acknowledge the doctors in the Department of Neurology, the Second Hospital of Tianjin Medical University, who gave us help to complete this study.

Contributors XL contributed significantly to conceived and designed the study and revise manuscript. ML contributed to the conception of the study and revised the manuscript. XL and ML are co-correspondence authors. XX performed the data analyses and wrote the manuscript. PW collected the data from the survey. SZ helped collect the data. LW helped perform the analysis with constructive discussions.

Funding This work is supported by the key project in the Science and Technology Foundation of Tianjin Health and Family Planning (15KG136) and the Natural Science Foundation of Tianjin (16JCYBJC25500).

Competing interests None declared.

Patient consent Obtained.

Ethics approval Ethics Committee in the Second Hospital of Tianjin Medical University.

Provenance and peer review Not commissioned; externally peer reviewed.

Data sharing statement № additional unpublished data are available.

Open Access This is an Open Access article distributed in accordance with the Creative Commons Attribution Non Commercial (CC BY-NC 4.0) license, which permits others to distribute, remix, adapt, build upon this work non-commercially, and license their derivative works on different terms, provided the original work is properly cited and the use is non-commercial. See: http://creativecommons.org/ licenses/by-nc/4.0/ 
(c) Article author(s) (or their employer(s) unless otherwise stated in the text of the article) 2017. All rights reserved. No commercial use is permitted unless otherwise expressly granted.

\section{REFERENCES}

1. Norrving B, Kissela $B$. The global burden of stroke and need for a continuum of care. Neurology 2013;80(3 Suppl 2):S5-S12.

2. Kim JS. Stroke in Asia: a global disaster. Int J Stroke 2014;9:856-7.

3. Jia Q, Liu LP, Wang YJ. Stroke in China. Clin Exp Pharmacol Physiol 2010;37:259-64.

4. Miller EL, Murray L, Richards L, et al. Comprehensive overview of nursing and interdisciplinary rehabilitation care of the stroke patient: a scientific statement from the American Heart Association. Stroke 2010;41:2402-48.

5. Lawler M LCT, Banks I, Conte P, et al. European Cancer Concord (ECC). A Bill of Rights for patients with cancer in Europe. Lancet Oncol 2014;15:258-60.

6. Nici L. A Bill of "Right" for patients with COPD: the "right" therapy for the "right" patient at the "right" time. Thorax 2010;65:2-3.

7. Damrow J, Gaarder K, Chopra S, et al. Global stroke bill of rights. Int J Stroke 2014;9:964.

8. Davis S, Norrving B. World Stroke Day: one world voice for stroke. Int J Stroke 2013;8(Suppl A1003):2-3.

9. TftGBo R. World stroke organization web site. $2015 \mathrm{http}: / / \mathrm{www}$. world-stroke.org/newsletter/latest-updates/18-news/latest-updates/ 261-toolkit-for-the-global-bill-of-rights:Accessed

10. McKevitt C, Fudge N, Redfern J, et al. Self-reported long-term needs after stroke. Stroke 2011;42:1398-403.

11. Wu X, Min L, Cong L, et al. Sex differences in health-related quality of life among adult stroke patients in Northeastern China. $J$ Clin Neurosci 2014;21:957-61.

12. Walsh ME, Galvin R, Loughnane $\mathrm{C}$, et al. Community re-integration and long-term need in the first five years after stroke: results from a national survey. Disabil Rehabil 2015;37:1-5.

13. Chau JP, Thompson DR, Chang AM, et al. Depression among Chinese stroke survivors six months after discharge from a rehabilitation hospital. J Clin Nurs 2010;19:3042-50.

14. Ekstam L, Johansson U, Guidetti S, et al. The combined perceptions of people with stroke and their carers regarding rehabilitation needs 1 year after stroke: a mixed methods study. BMJ Open 2015;5:e006784.

15. Matsuzaki S, Hashimoto M, Yuki S, et al. The relationship between post-stroke depression and physical recovery. J Affect Disord 2015;176:56-60.

16. Park GY, Im S, Oh $\mathrm{CH}$, et al. The association between the severity of poststroke depression and clinical outcomes after first-onset stroke in Korean patients. Gen Hosp Psychiatry 2015;37:245-50.

17. Broomfield NM, Quinn TJ, Abdul-Rahim AH, et al. Depression and anxiety symptoms post-stroke/TIA: prevalence and associations in cross-sectional data from a regional stroke registry. BMC Neurol 2014;14:198.

18. Harrison M, Ryan T, Gardiner C, et al. Psychological and emotional needs, assessment, and support post-stroke: a multi-perspective qualitative study. Top Stroke Rehabil 2017;24:1-7.
19. Kernan WN OB, Black HR, Bravata DM, et al. American Heart Association Stroke Council, Council on Cardiovascular and Stroke Nursing, Council on Clinical Cardiology, and Council on Peripheral Vascular Disease. Guidelines for the prevention of stroke in patients with stroke and transient ischemic attack: a guideline for healthcare professionals from the American Heart Association/American Stroke Association. Stroke 2014;45:2160-236.

20. Lip GY, Lane DA. Stroke prevention in atrial fibrillation: a systematic review. JAMA 2015;313:1950-62.

21. Chen L, Xiao LD, De Bellis A. First-time stroke survivors and caregivers' perceptions of being engaged in rehabilitation. J Adv Nurs 2016;72:73-84.

22. Kamalakannan S, Gudlavalleti Venkata M, Prost A, et al. Rehabilitation Needs of Stroke Survivors After Discharge From Hospital in India. Arch Phys Med Rehabil 2016;97:1526-32.

23. Niu JW, Yuan J, Gao S, et al. Low awareness of stroke guidelines and preference for Chinese herbs in community physicians: a national survey in China. Ann Trans/ Med 2014;2:76.

24. Lindsay P, Furie KL, Davis SM, et al. World Stroke Organization global stroke services guidelines and action plan. Int J Stroke 2014;9(Suppl A100):4-13.

25. Skolarus LE, Burke JF, Brown DL, et al. Understanding stroke survivorship: expanding the concept of poststroke disability. Stroke 2014;45:224-30.

26. Zhang L, Yan T, You L, et al. Barriers to activity and participation for stroke survivors in rural China. Arch Phys Med Rehabil 2015;96:1222-8.

27. Feigin VL FM, Krishnamurthi R, Mensah GA, et al. Global Burden of Diseases, Injuries, and Risk Factors Study 2010 (GBD 2010) and the GBD Stroke Experts Group. Global and regional burden of stroke during 1990-2010: findings from the Global Burden of Disease Study 2010. Lancet 2014;383:245-54.

28. Hachinski V, Donnan GA, Gorelick PB, et al. Stroke: working toward a prioritized world agenda. Stroke 2010;41:1084-99.

29. Nakibuuka J, Sajatovic M, Katabira E, et al. Knowledge and Perception of Stroke: A Population-Based Survey in Uganda. ISRN Stroke 2014;2014:1-7.

30. Hickey A, O'Hanlon A, McGee H, et al. Stroke awareness in the general population: knowledge of stroke risk factors and warning signs in older adults. BMC Geriatr 2009;9:35.

31. Akiyama $\mathrm{H}$, Hasegawa $\mathrm{Y}$. Knowledge of transient ischemic attack among the Japanese. J Stroke Cerebrovasc Dis 2013;22:457-64.

32. Zeng $\mathrm{Y}, \mathrm{He} \mathrm{GP}, \mathrm{Yi} \mathrm{GH}$, et al. Knowledge of stroke warning signs and risk factors among patients with previous stroke or TIA in China. $J$ Clin Nurs 2012;21:2886-95.

33. Hickey A, Holly D, McGee H, et al. Knowledge of stroke risk factors and warning signs in Ireland: development and application of the Stroke Awareness Questionnaire (SAQ). Int J Stroke 2012;7:298-306.

34. Hachinski V. World Stroke Day Proclamation. Stroke 2008;39:2409-20.

35. Tsai PC, Yip PK, Tai JJ, et al. Needs of family caregivers of stroke patients: a longitudinal study of caregivers' perspectives. Patient Prefer Adherence 2015;9:449-57. 